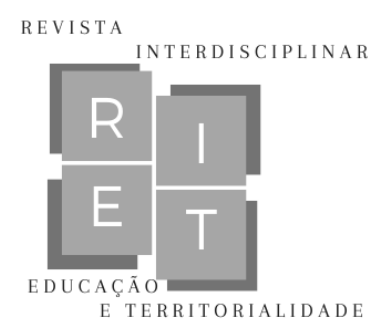

\title{
A utilização do aplicativo Hand Talk como Tecnologia Assistiva no ensino de alunos ouvintes: relato de experiência dentro do ensino remoto emergencial
}

The use of the Hand Talk application as Assistive Technology in teaching hearing students: report of an experience in remote emergency teaching

El uso de la aplicación Hand Talk como tecnología de asistencia en la enseñanza de los estudiantes oyentes: informe de la experiencia dentro de la enseñanza remota de emergencia

Luís Gustavo Rodrigues Marcondes Programa de Pós-Graduação em Educação, Universidade Federal de São Carlos campus Sorocaba

(UFSCar)

Sorocaba, São Paulo, Brasil

E-mail: lgrmarcondes@estudante.ufscar.br ORCID: 0000-0002-8588-4444

\begin{abstract}
Resumo: Essa narrativa tem como intenção relatar o desenvolvimento um projeto pedagógico desenvolvido no período de trabalho remoto, tendo como foco o uso de ferramentas assistivas no ensino de estudantes sem deficiência. Com a intenção de sensibilizar e conscientizar os estudantes de uma escola da rede pública acerca da importância dos processos de comunicação em suas mais variadas formas e a respeito das dificuldades enfrentadas pela comunidade surda para a comunicação com a comunidade ouvinte foi possibilitado o contato e uso da ferramenta assistiva Hand Talk, que permitiu que os estudantes tivessem contato com a Língua Brasileira de Sinais - LIBRAS - e refletissem acerca do seu uso cotidiano, além de possibilitar o contato real dos participantes desse projeto com situações sociais de comunicação por meio da LIBRAS. Durante o desenvolvimento do projeto, pode-se constatar que, após o contato inicial com essa forma de comunicação, possibilitado pelo uso de uma tecnologia assistiva, estudantes e responsáveis demonstraram uma maior compreensão das dinâmicas comunicativas da comunidade surda e tornaram-se empáticos e conscientes não apenas da necessidade de inclusão social dos surdos, mas também da necessidade dos indivíduos ouvintes serem preparados para as mais diversas situações de comunicação social entre surdos e ouvintes.

Palavras-chave: Língua Brasileira de Sinais. Alunos Ouvintes. Tecnologias assistivas.
\end{abstract}

Abstract: This narrative intends to report the development of a pedagogical project developed in the period of remote work, focusing on the use of assistive tools in teaching students without disabilities. With the intention of sensitizing and raising awareness of students from a public school about the importance of communication processes in its various forms and the difficulties faced by the deaf community to communicate with the speaking community, it was made possible the contact and use of the assistive tool Hand Talk, which allowed students to have contact with the Brazilian Sign Language - LIBRAS -

RIET- ISSN 2676-0355, Dourados, v. 2, n. 2, p. 205 a 217, jan./jun., 2021 


\section{A utilização do aplicativo Hand Talk como Tecnologia Assistiva no ensino de alunos ouvintes: relato de experiência dentro do ensino remoto emergencial}

and reflect on their daily use, in addition to enabling the real contact of the participants of this project with social communication situations through LIBRAS. Through the development of the project, it can be seen that after the initial contact with this form of communication, made possible by the use of an assistive technology, students and guardians showed a greater understanding of the dynamics of communication of the deaf community and became empathetic and aware not only of the need for social inclusion of the deaf, but also the need for hearing individuals to be trained for the most diverse situations of social communication between deaf and hearing people.

Keywords: Brazilian Sign Language. Hearing students. Assistive technologies.

Resumen: Este relato pretende dar cuenta del desarrollo de un proyecto pedagógico desarrollado en el período de trabajo a distancia, centrado en el uso de herramientas de ayuda en la enseñanza de alumnos sin discapacidad. Con la intención de sensibilizar y concienciar a los estudiantes de una escuela pública sobre la importancia de los procesos de comunicación en sus diversas formas y las dificultades que enfrenta la comunidad sorda para comunicarse con la comunidad hablante, se hizo posible el contacto y el uso de la herramienta de asistencia Hand Talk, que permitió a los estudiantes tener contacto con la Lengua de Signos Brasileña - LIBRAS - y reflexionar sobre su uso diario, además de permitir el contacto real de los participantes de este proyecto con situaciones sociales de comunicación a través de LIBRAS. A través del desarrollo del proyecto, se puede observar que tras el contacto inicial con esta forma de comunicación, posibilitada por el uso de una tecnología de ayuda, los alumnos y tutores demostraron una mayor comprensión de la dinámica comunicativa de la comunidad sorda y se volvieron empáticos y conscientes no sólo de la necesidad de inclusión social de los sordos, sino también de la necesidad de que las personas oyentes estén capacitadas para las más diversas situaciones de comunicación social entre sordos y oyentes.

Palabras clave: Lengua de signos brasileña. Estudiantes oyentes. Tecnologías de asistencia.

Data de recebimento: $26 / 03 / 2021$

Data de aprovação: 10/06/2021

DOI: $10.30612 /$ riet.v\%vi\%i.14453

\section{A linguagem como forma de inserção social}

Ao nos atentarmos para aspectos históricos percebemos que até meados do século $\mathrm{XV}$ as práticas educativas com surdos eram inexistentes, uma vez que eles eram considerados ineducáveis. Partindo da perspectiva da condição humana através do pensamento aristotélico, aqueles que não são dotados da audição são incapazes de falar e uma vez que não sejam capazes de produzir linguagem oral, não são capazes de pensar, assim sendo, não devem ser considerados humanos (Moura, 1996, p. 16).

Segundo Vygotsky (2001), a linguagem é que garante a estruturação dos processos cognitivos e, isto posto, ela torna-se fundamental para a constituição e desenvolvimento dos indivíduos. Ao definir a Língua Brasileira de Sinais (LIBRAS), Meireles (2015) estabelece

RIET-ISSN 2676-0355, Dourados, v. 2, n. 2, p. 205 a 217, jan./jun., 2021 


\section{A utilização do aplicativo Hand Talk como Tecnologia Assistiva no ensino de alunos ouvintes: relato de experiência dentro do ensino remoto emergencial}

que a LIBRAS é natural da comunidade surda, e como língua apresenta regras morfológicas, sintáticas, semânticas e pragmáticas específicas. Tem como principal funcionalidade a capacidade de possibilitar que indivíduos pertencentes à comunidade surda se comuniquem, e que, realizado o processo de comunicação, desenvolvam-se cognitivamente.

Em pesquisa divulgada pelo Instituto Brasileiro de Geografia e Estatística - IBGE no ano de 2020 verificou-se que mais de 10 milhões de pessoas possuem algum problema relacionado à surdez. Esse total representa $5 \%$ de toda a população do nosso país e deste total, 2,7 milhões de pessoas não ouvem nada. Vasconcelos (2007) em suas pesquisas sobre a formação o professor como sujeito transformador afirma que:

Nesse sentido, ainda que a comunidade escolar e/ou grupo de alunos não conte com um estudante surdo, ela deve ocupar-se com a preparação de seus estudantes para que possam exercer efetivo exercício de sua cidadania fora do âmbito escolar. Junto a isso, sendo a escola um espaço de disseminação para o conhecimento historicamente acumulado, recai sobre ela a responsabilidade de se adequar a sociedade a fim de possibilitar a formação dos sujeitos de forma correspondente a realidade da sociedade globalizada na qual ele está inserido (VASCONCELOS, 2007, p. 45).

De acordo com a Base Nacional Comum Curricular, documento que atualmente estabelece orientações sobre os processos didático-pedagógicos em todo o território nacional e apresenta competências gerais apontadas como essenciais para a formação integral dos estudantes, o ensino de LIBRAS se coloca como parte do desenvolvimento da competência geral 4:

Comunicação: Utilizar diferentes linguagens - verbal (oral ou visualmotora, como Libras, e escrita), corporal, visual, sonora e digital -, bem como conhecimentos das linguagens artística, matemática e científica, para se expressar e partilhar informações, experiências, ideias e sentimentos em diferentes contextos, além de produzir sentidos que levem ao entendimento mútuo (BRASIL, 2017).

Ainda observando as regulamentações e direcionamentos presentes na Base Nacional Comum Curricular, do ponto de vista da formação integral e crítica dos estudantes frente a essa sociedade tecnológica na qual estamos inseridos, a BNCC apresenta uma preocupação com o letramento digital em sua competência geral 5 que estabelece que é necessário ao aluno: 


\section{A utilização do aplicativo Hand Talk como Tecnologia Assistiva no ensino de alunos ouvintes: relato de experiência dentro do ensino remoto emergencial}

Compreender, utilizar e criar tecnologias digitais de informação e comunicação de forma crítica, significativa, reflexiva e ética nas diversas práticas sociais (incluindo as escolares) para se comunicar, acessar e disseminar informações, produzir conhecimentos, resolver problemas e exercer protagonismo e autoria na vida pessoal e coletiva (BRASIL, 2017).

Considerando a formação integral de estudantes prevista nos referencias que regem a Base Nacional Comum Curricular (2017) e a Lei de Diretrizes e Bases da Educação Nacional (LDB) de 1996, a aplicação e desenvolvimento desta prática pedagógica se coloca como uma possibilidade para essa formação. A relevância dessa prática justifica-se quando consideramos a necessidade, na formação integral, de preparar alunos ouvintes para uma efetiva inserção na nossa sociedade - cada vez mais tecnológica e plural - de modo que esses estudantes ouvintes possam, utilizando-se de tecnologias assistivas, inserir-se no universo da comunidade surda.

\section{Tecnologias assistivas: conceituação}

O momento no qual está inserida a sociedade moderna tem propiciado o avanço do uso das Tecnologias da Informação e Comunicação (TIC), com a utilização cada vez maior de ferramentas tecnológicas, cada vez mais capazes de realizar diversas funções. Uso esse que tem resultado em alterações no modo de vida de toda a sociedade global.

Tais alterações têm impactado também no que diz respeito às diversidades sociais, culturais e de qualquer outra ordem. Considerando que a escola é parte de um processo social, seu ambiente e os sujeitos que nela estão inseridos são atingidos por essas transformações, possibilitando uma superação dos diversos impedimentos, que por muito tempo, funcionaram como mecanismos de exclusão escolar.

Desse modo, "ir à escola passa a ser considerado como equivalente a ter circulação social, ser reconhecido como parte integrante da polis" (BAPTISTA, 2009, p. 7). Do ponto de vista da inclusão, o uso de ferramentas assistivas se coloca como uma possibilidade de aprimorar os processos de superação dos mecanismos de exclusão. Segundo o Comitê de Ajudas Técnicas, organizado pela Secretaria dos Direitos Humanos da Presidência da República:

Tecnologia Assistiva é uma área do conhecimento, de característica interdisciplinar, que engloba produtos, recursos, metodologias, estratégias, práticas e serviços que objetivam promover a funcionalidade, relacionada 


\section{A utilização do aplicativo Hand Talk como Tecnologia Assistiva no ensino de alunos ouvintes: relato de experiência dentro do ensino remoto emergencial}

à atividade e a participação de pessoas com deficiência, incapacidade ou mobilidade reduzida, visando sua autonomia, independência, qualidade de vida e inclusão social (GALVÃO FILHO et al, 2009, p. 26).

Assim sendo, pode-se compreender que os considerados recursos de tecnologia assistiva vão desde o uso de um lápis com empunhadura adaptada, chegando a sofisticados recursos digitais que tem sua utilização voltada a uma maior autonomia e independência à pessoa com deficiência.

\section{O aplicativo Hand Talk}

O Hand Talk caracteriza-se por um aplicativo disponível para uso em Smartphones e tablets, que tem como função a tradução em tempo real, de conteúdos em Língua Portuguesa para a Língua Brasileira de Sinais. O aplicativo converte arquivos escritos, em formato de áudio e imagem. Seu uso é possível desde que o dispositivo no qual esteja instalado possua conexão com a internet.

O Hand Talk apresenta um avatar em imagem 3D, chamado de Hugo. O avatar é responsável por demonstrar os movimentos dos sinais de LIBRAS, podendo ser girado em $360^{\circ}$ e ampliado, o que possibilita uma maior facilidade na observação dos movimentos do avatar. Pode ser caracterizado como uma ferramenta de consulta e pode auxiliar no processo de ensino da LIBRAS para alunos surdos e/ou ouvintes. Tal aplicativo foi desenvolvido no Brasil e foi premiado pela Organização das Nações Unidas como o melhor aplicativo social do ano de 2013.

\section{Percursos do trabalho pedagógico}

\section{Caracterização da prática pedagógica e dos sujeitos envolvidos}

O texto que aqui se apresenta, relata a experiência de um projeto pedagógico que foi desenvolvido com 18 alunos ouvintes que cursam o $5^{\circ}$ ano do Ensino Fundamental de uma unidade escolar inserida no município de Araçoiaba da Serra, no interior do estado de São Paulo. Os alunos atendidos caracterizam-se por um público heterogêneo, advindos de diferentes bairros do município aqui citado, o que resulta em uma comunidade escolar bastante diversificada dos pontos de vista econômicos, sociais e culturais.

O objetivo central dessa prática foi o de apresentar aos alunos a Língua Brasileira de Sinais e envolvê-los em situações nas quais seria necessário que fizessem o uso da LIBRAS como comunicação com outros estudantes da mesma turma de alunos. Como objetivos 


\section{A utilização do aplicativo Hand Talk como Tecnologia Assistiva no ensino de alunos ouvintes: relato de experiência dentro do ensino remoto emergencial}

complementares a prática pedagógica ocupou-se com a conscientização dos alunos ouvintes acerca das dificuldades encontradas pela comunidade surda inserida em ambientes que não são inclusivos, levar os estudantes a conhecer sobre a LIBRAS, sua origem, suas especificidades e sua importância para a inclusão social.

Preocupou-se ainda com oportunizar que alunos ouvintes estejam preparados para comunicarem-se com indivíduos surdos, e que para esse processo, sejam capazes de usar a ferramenta assistiva Hand Talk como facilitadora desse processo de aprendizagem e inserção social.

\section{Envolvimento dos estudantes: a curiosidade como motor do processo de ensino- aprendizagem}

O despertar inicial para a realização e aplicação desse projeto ocorreu durante a primeira semana de aula do ano letivo de 2020. Enquanto alunos retornavam ansiosos para a escola e trocavam informações sobre as férias em conversas animadas com os colegas, um dos estudantes decidiu mostrar seu novo material escolar, que iria acompanhá-lo naquele ano. Ao exibir o seu caderno a um colega de classe, os dois passaram a observar a capa, que trazia a ilustração de um super-herói e, ao abrir o caderno, depararam-se com uma página ilustrada, cheia de "desenhos de mão" como disse um dos alunos. Sem entender muito bem do que eram aquelas ilustrações, recorrem a um outro colega de sala, que ao ser questionado, prontamente responde "é língua de surdo".

Ao perceber a movimentação dos alunos em torno da temática levantada, tornou-se visível que naquele momento todos os estudantes estavam mobilizados para saber mais acerca daquele assunto, uma vez que a demonstração de interesse e envolvimento por parte dos estudantes se mostra como uma oportunidade profícua de aprendizagem.

Tendo em vista que uma das tarefas fundamentais de toda prática educativa deve ser o desenvolvimento da curiosidade crítica, curiosidade essa que possibilita que o aprendiz se aproxime do conhecimento sem que se submeta a ele, e percebendo a movimentação e mobilização da grande maioria dos alunos que integravam aquela turma, o professor desperto pelos estudantes, reorganiza o caminhar da aula e volta-se a ouvir os alunos acerca da temática estabelecida. 


\section{A utilização do aplicativo Hand Talk como Tecnologia Assistiva no ensino de alunos ouvintes: relato de experiência dentro do ensino remoto emergencial}

Partindo dessa mobilização iniciou-se a idealização do projeto, porém frente ao cenário de suspensão das aulas presenciais como consequência da Pandemia causada pelo novo COVID-19 a organização não pode ser colocada em prática. Após o estabelecimento do atendimento remoto aos alunos, o professor retomou a idealização do projeto, buscando agora, adequá-lo à nova realidade de interação com os alunos. Cabe ressaltar aqui que a execução do projeto se deu entre os meses de abril e agosto do ano letivo de 2020.

Os processos de organização didática, visando a relação de ensino aprendizagem por meio das relações entre professor-aluno e aluno-aluno, tem como referencial os apontamentos de Zabala (1998), que define sequência didática como "um conjunto de atividades ordenadas, estruturadas e articuladas para a realização de certos objetivos educacionais, que têm um princípio e um fim conhecidos tanto pelos professores como pelos alunos." (ZABALA, 1998, p.18). Para o autor as fases de uma sequência didática são: atividade motivadora, explicação de perguntas ou problemas, respostas intuitivas, observação de dados e expressão e comunicação. Essas etapas são descritas abaixo em quatro momentos.

\section{Primeiro momento (Atividade motivadora - Mobilização de alunos e responsáveis)}

Inicialmente, de forma a contextualizar o tema proposto por esse projeto educacional, os estudantes receberam, por meio do aplicativo WhatsApp um vídeo gravado pelo professor no qual ele fazia sua apresentação pessoal em LIBRAS. O professor então entrou em contato com os estudantes a fim de verificar se eles haviam compreendido a comunicação realizada por meio o vídeo.

Os estudantes então relataram que não conseguiram compreender, mas apontaram que identificaram que o professor estava utilizando "a linguagem dos surdos" "o jeito que os mudos falam" e "a língua de sinais". O professor então enviou orientações aos estudantes, esclarecendo que o vídeo enviado se tratava de uma apresentação pessoal utilizando a LIBRAS e realizou uma proposta aos estudantes, provocando-os para que eles respondessem ao vídeo se apresentado em LIBRAS. As crianças então se mostraram entusiasmadas na realização do vídeo, porém se mostravam preocupadas por não saberem como utilizar a LIBRAS.

Em seguida, por meio do atendimento via WhatsApp, os responsáveis pelos estudantes foram informados da realização do projeto de comunicação em LIBRAS e foram

RIET- ISSN 2676-0355, Dourados, v. 2, n. 2, p. 205 a 217, jan./jun., 2021 


\section{A utilização do aplicativo Hand Talk como Tecnologia Assistiva no ensino de alunos ouvintes: relato de experiência dentro do ensino remoto emergencial}

orientados a realizar o download do aplicativo gratuito Hand Talk, disponível de forma gratuita na loja de aplicativos dos aparelhos Smartphone.

Após esse processo, as crianças receberam explicações acerca do funcionamento do aplicativo, algo bastante simples para a grande maioria dos alunos que estão familiarizados com o uso de aplicativos. Então, utilizando o aplicativo e vídeos do Youtube disponibilizados pelo professor, gravaram seu vídeo de apresentação pessoal e enviaram ao professor e a um colega de turma.

\section{Segundo momento (Explicação de perguntas ou problemas - Sensibilização, contextualização e relevância do uso social das atividades propostas)}

Dando continuidade ao projeto e com a necessidade de realizar um processo de sensibilização e mobilização por parte dos alunos e de seus responsáveis, foram enviados vídeos e textos informativos sobre a população surda em nosso país, suas dificuldades de inclusão e sua luta por equidade. Esses textos e vídeos foram lidos e assistidos tanto pelos estudantes quanto por seus responsáveis.

As devolutivas realizadas pelos estudantes e por seus responsáveis demonstravam que o conhecimento que eles possuíam acerca dos processos de inclusão social da comunidade surda, suas dificuldades em se inserir em uma sociedade que, em diversas situações, não cria dispositivos e possibilidades que garantam a efetiva participação dessa comunidade no cotidiano diverso.

Elas demonstravam também a sensibilização que as leituras e vídeos trouxeram aos envolvidos na realização dessa prática pedagógica. Nesse momento, ocorreu uma mobilização que atingiu não apenas estudantes, mas também os responsáveis por eles, tornando-os inclinados a participar, juntamente a seus filhos e filhas, das etapas propostas pelo professor.

Terceiro momento (Organização de dados - Participação, reflexão e desenvolvimento da autonomia dos alunos)

Já familiarizados com a temática do projeto a ser desenvolvido e mobilizados para a participação nele, os alunos receberam a proposta da segunda atividade. Utilizando os recursos do aplicativo Hand Talk e o celular, as crianças foram orientadas a produzir um vídeo utilizando a Língua de sinais, no qual deveriam contar quais eram seus alimentos favoritos, porém, esse vídeo não foi enviado ao professor. Cada estudante recebeu a

RIET- ISSN 2676-0355, Dourados, v. 2, n. 2, p. 205 a 217, jan./jun., 2021 


\section{A utilização do aplicativo Hand Talk como Tecnologia Assistiva no ensino de alunos ouvintes: relato de experiência dentro do ensino remoto emergencial}

orientação de que deveria escolher um outro colega de classe para enviá-lo e assim realizar uma situação real de comunicação. Os responsáveis pelos alunos participaram auxiliando as crianças no processo de filmagem e edição dos vídeos caseiros.

Dentro desse processo de comunicação iniciado na relação aluno-aluno, o professor interagiu como mediador, auxiliando e colaborando com os estudantes que apresentaram dificuldades na compreensão dos vídeos recebidos e/ou na elaboração das situações de comunicação. Essas interações ocorreram de forma assíncrona, com orientações via WhatsApp e de forma síncrona, com a realização de videoconferências, nas quais os alunos puderam expor suas dúvidas, questionamentos e compartilhar com o professor e com outros colegas de turma as experiências dentro da realização de cada etapa do projeto.

Dando continuidade a esse processo de comunicação, os alunos continuaram com suas conversas por meio de vídeos em LIBRAS enviados via WhatsApp com diversos temas: que tipo de animal de estimação o aluno possui, saudações, gostos pessoais, informações sobre temas estudados nas aulas, entre outros. A cada vídeo que o aluno recebia de um colega, ele deveria continuar a conversa, respondendo as questões levantadas e gerando novas questões a serem respondidas.

\section{Quarto momento (Expressão e comunicação -Fechamento)}

Neste período do desenvolvimento do projeto, os estudantes mostravam-se familiarizados com o uso inicial da LIBRAS em situações sociais. Com a intenção de concluir o projeto aqui proposto, foi solicitado aos estudantes que produzissem um vídeo breve, contando como estava sendo participar dessas atividades, o que estava aprendendo e como o aprendizado de LIBRAS poderia ser utilizado, por eles, fora do ambiente escolar.

Esses vídeos deveriam ser enviados ao professor por meio da utilização do aplicativo de mensagens. Foram recebidos vídeos diversos, nos quais os estudantes contavam suas experiências na realização das atividades do projeto, suas dificuldades nas situações de comunicação em LIBRAS. Contaram o que aprenderam, como passaram a compreender a importância da presença do intérprete de LIBRAS, que muitas crianças citaram terem observado nas diversas lives que acompanharam durante o período de isolamento social.

Junto aos vídeos enviados pelos alunos, alguns responsáveis resolveram também compartilhar suas impressões, dificuldades e aprendizados durante a participação em todas as etapas, auxiliando seus filhos. Foram enviados vídeos por diversos responsáveis, 


\section{A utilização do aplicativo Hand Talk como Tecnologia Assistiva no ensino de alunos ouvintes: relato de experiência dentro do ensino remoto emergencial}

comunicando-se em LIBRAS, apontando um despertar e uma mobilização para pensar sobre os mais diversos processos de inclusão da comunidade surda em nossa sociedade. Dentro das etapas de desenvolvimento do projeto, de modo interdisciplinar, todos os componentes foram abordados considerando que as temáticas dos processos de comunicação.

\section{O uso de LIBRAS por alunos ouvintes como processo de inclusão social}

O processo de ensino-aprendizagem da Língua Brasileira de Sinais tornou-se, no decorrer do desenvolvimento deste projeto, uma temática extremamente necessária. As reflexões referentes às vivências ocorridas neste projeto ultrapassaram a proposta de inclusão, mas levaram a reflexão do processo do ensino bilíngue tendo LIBRAS como segunda língua.

Embora o ensino da LIBRAS seja, em nosso país, previsto pela Lei de Diretrizes e Bases da Educação (BRASIL, 1996) em seu artigo 58, esse processo de ensino está voltado ao estudante surdo, e não ao ensino bilingue para alunos ouvintes. Desse ponto de vista, deparamo-nos com uma grande insuficiência histórica dos processos de ensino da LIBRAS como segunda língua.

$\mathrm{Na}$ inclusão dos alunos com deficiência, muitos desafios são encontrados no ambiente escolar, tais como: barreiras arquitetônicas, metodológicas, atitudinais, sociais, econômicas, entre outras. De forma mais específica, quando consideramos a inclusão dos surdos, temos de considerar o impacto de uma outra barreira, que é a linguística. A língua de um povo, mais do que o seu processo de comunicação direta, é um dos principais elementos de constituição de sua identidade e cultura. Desse modo, ao nos depararmos com uma barreira linguística, é imprescindível compreender que ela se torna um impedimento na formação integral do ser humano.

Nesse sentido, mais do que capacitar o indivíduo surdo para comunicar-se com os demais membros da comunidade surda, é necessário que os indivíduos ouvintes tornem-se capazes de realizar a sua comunicação com os surdos. Do ponto de vista da formação integral do estudante, não se pode esperar que o ensino de LIBRAS se faça presente apenas em turmas de estudantes que contam com um membro surdo.

A escola, ao se preocupar com a formação integral do indivíduo, deve segundo a BNCC, deve possibilitar o desenvolvimento global dos estudantes, compreendendo "a 


\section{A utilização do aplicativo Hand Talk como Tecnologia Assistiva no ensino de alunos ouvintes: relato de experiência dentro do ensino remoto emergencial}

complexidade e a não linearidade desse desenvolvimento, rompendo com visões reducionistas que privilegiam ou a dimensão intelectual (cognitiva) ou a dimensão afetiva" (BNCC, 2017, p. 14). Ao considerarmos que a formação integral da forma que aqui é apresentada, a educação deve ter como norte a preparação do indivíduo para o pleno exercício de sua cidadania, nos mais diversos ambientes, esferas e situações, fica claro que o ensino do ouvinte para que possa se comunicar com o surdo deve ser uma preocupação da formação escolar.

\section{Reflexões e aprendizados}

A aplicação do projeto aqui apresentado mostrou-se significativa quando observamos a participação e engajamento dos alunos e de seus responsáveis. Os alunos participantes demonstram, ao final da realização das etapas desenvolvidas, maior consciência da necessidade de comunicação de surdos. Mostram-se sensibilizados a necessidade de inclusão desses indivíduos e refletem acerca do fato de que, mesmo que não tenham contato na turma como um aluno surdo, pode ser que agora que iniciarão os anos finais do ensino fundamental em outra unidade escolar, possam vir a ter contato com surdos dentro da escola.

Nos momentos de socialização das etapas de desenvolvimento do projeto, os alunos demonstram maior compreensão acerca da Língua Brasileira de Sinais e de sua complexidade, relatam que achavam que ela se resumia ao alfabeto e que agora, quando estão assistindo um vídeo que conta com intérprete de LIBRAS, entendem como isso é necessário para a comunidade surda.

Com a conclusão dessa proposta pedagógica, constata-se que o uso das tecnologias associados aos processos de ensino são de grande relevância. Foi a tecnologia que garantiu todas as etapas de execução desse projeto nesse momento, visto que, no período de distanciamento social no qual nos encontramos, foi exclusivamente pelo uso da internet e de ferramentas como Smartphones e aplicativos que esse desenvolvimento se tornou possível.

Constata-se ainda que o processo de inclusão das ferramentas assistivas dentro dos ambientes escolares possibilitam avanços na formação integral de todos. Tais ferramentas possibilitam que profissionais da educação possam, dentro de sua prática docente, trazer uma movimentação e um despertar para o envolvimento não apena dos estudantes, mas de toda a comunidade escolar.

\section{5}

RIET-ISSN 2676-0355, Dourados, v. 2, n. 2, p. 205 a 217, jan./jun., 2021 


\section{A utilização do aplicativo Hand Talk como Tecnologia Assistiva no ensino de alunos ouvintes: relato de experiência dentro do ensino remoto emergencial}

Reflete-se ainda que essas tecnologias possibilitam variadas aprendizagens em diferentes contextos. Como sendo um caminho para a formação integral cidadã, a tecnologia traz um grande impacto, mas é preciso que esses usos sejam direcionados, organizados e planejados, é imprescindível também o preparo dos educadores para que compreendam que a inserção do uso das tecnologias assistivas não garante os processos de inclusão. A democratização da inclusão encontrou nas tecnologias assistivas mais um caminho, mais uma possibilidade, mas sem a implementação de políticas públicas que visem a formação dos profissionais da educação, o investimento no desenvolvimento e aprimoramento dessas ferramentas e a democratização do acesso a elas, muito pouco pode ser alcançado nos processos de inserção e emancipação das pessoas com deficiência, e aqui, destacamos a inclusão da comunidade surda.

Concluímos que o projeto contribuiu na formação desses estudantes, uma vez que possibilitou o desenvolvimento de competências socioemocionais, intrapessoais e interpessoais indispensáveis para que a escola atinja o seu objetivo de formação integral dos estudantes. Com essa narrativa, temos a intenção de contribuir para os processos de fortalecimento e afirmação da necessidade de estudos acerca da utilização das Tecnologias Assistivas no processo de ensino-aprendizagem de alunos com e sem deficiência.

\section{Referências}

BAPTISTA, Cláudio Roberto. Inclusão e escolarização: múltiplas perspectivas. Porto Alegre: Mediação, 2009

BRASIL. Ministério da Educação. Lei de Diretrizes e Bases da Educação Nacional. Lei n . 9.394/96. (1996).

BRASIL. Instituto Brasileira de Geografia e Estatística. IBGE. Censo demográfico. Brasil, 2010.

BRASIL. Ministério da Educação. Secretaria da Educação Básica. Base nacional comum curricular. Brasília, DF, 2017.

CRUZ, Gilmar de Carvalho. Formação continuada de professores em ambiente escolar inclusivo. Londrina: EDUEL, 2008.

GALVÃO FILHO, T. et al. Conceituação e estudo de normas. In: Brasil, Subsecretaria Nacional de Promoção dos Direitos da Pessoa com Deficiência. Comitê de Ajudas Técnicas. Tecnologia assistiva. Brasília: Corde, 2009. 138p.

HOFFMAN, Jussara. Avaliação: mito \& desafio. Uma perspectiva construtivista. Porto Alegre: Mediação, 2003. 
A utilização do aplicativo Hand Talk como Tecnologia Assistiva no ensino de alunos ouvintes: relato de experiência dentro do ensino remoto emergencial

LUCKESI, Cipriano Carlos. Avaliação da aprendizagem escolar: estudos, proposições. 3.ed. São Paulo: Cortez, 1996.

MENDES, Ana Quelle Silva; FIGUEREDO, Fernanda.; RIBEIRO, Antônio Carlos. Inclusão de alunos surdos na escola regular: Aspectos linguísticos e pedagógicos. Revista da iniciação cientifica - RIC Cairu. Jun. 2015, vol. 02, nº 02, p. 33-46, Issn 2258-1166.

VASCONCELOS, Celso Santos. Para onde vai o professor? Resgate do professor como sujeito da transformação. $12^{\mathrm{a}}$ ed. São Paulo: Libertad, 2007.

VYGOTSKY, Lev Semionovitch. A construção do pensamento e da linguagem. São Paulo: Martins Fontes, 2001.

ZABALA, Antoni. A prática educativa: como ensinar. Porto Alegre: Artmed, 1998. 